\title{
Older people as partners in assistive technology research: The use of focus groups in the design process
}

\author{
Jane Seale ${ }^{\mathrm{a}, *}$, Claudine McCreadie ${ }^{\mathrm{b}}$, Alan Turner-Smith ${ }^{\mathrm{a}}$ and Anthea Tinker ${ }^{\mathrm{b}}$ \\ ${ }^{a}$ Centre of Rehabilitation Engineering, Kings College, London, UK \\ ${ }^{\mathrm{b}}$ Age Concern Institute of Gerontology, Kings College, London, UK
}

\begin{abstract}
There is an increasing recognition that older people are capable of being critical and active consumers of assistive technologies. This has led to the proposition that older people should be involved in their design and evaluation. In this paper we will describe a focus group methodology used to help older people identify and describe the nature of the mobility-related problems that they encounter, and then put forward ideas for their resolution, which might usefully be addressed by innovative assistive technology research. This methodology was used with four groups of older people and the results revealed that the problems that were most frequently identified as difficult were bending and reaching, climbing stairs, and finding information. While focus group participants were able to suggest both existing and new solutions to these identified problems the researchers consider that further exploration of the methodology used in this study is needed in order to validate the choice of tools, the composition of the focus groups and the process by which researchers decide which of the potential solutions should be developed further.
\end{abstract}

\section{Introduction}

European Projects such as USDAT and FORTUNE [1,2] are presenting Assistive Technology researchers with a clear message regarding the importance of involving users in the design and development process. For example, the FORTUNE project developed a curriculum framework that could be used to teach users about the principles of research and development and thus empower them to become more involved in future research and development activities.

With the growing acknowledgement of the importance of user involvement comes a growing recognition of the importance of involving older users in the research and development of new assistive technolo-

*Address for correspondence: Dr Jane K. Seale, Centre of Rehabilitation Engineering, Department of Medical Engineering and Physics, Kings College London, Denmark Hill, London SE5 9RS, UK. Tel.: +44 207346 1653; Fax: +44 207346 1651; E-mail: jane.seale@kcl.ac.uk. gies [3-5]. There are three main reasons for involving older users in assistive technology research. Firstly, it might help to avoid the application of technology that creates more problems than it solves [6]. The involvement of the user in the initial stages of the research and development process anchors the technology firmly in their views and experience. Secondly, it may help to promote the view that older people are not "a problem" for which technology may contribute an answer. They are individuals with needs, and also most importantly with capacities and with tastes [6,7]. Finally, the "Design for All" philosophy [8] would suggest that what works for older people will work better for everyone. This constitutes recognition of the economic reality of assistive technology markets:

"the market for technology will develop only when useful applications appear, not just for the primary or disabled user, but for everyone" [7].

The participation of older people in assistive technology research is therefore essential in developing cost-effective technology, which has a direct impact 
on older people's quality of life. Increasingly, it has been recognised that this means understanding older people's "needs, preferences and aspirations" and developing technical solutions that match this. Rietsema and Melenhorst [9] argue that "the starting point of the design cycle is the daily living and the spontaneous behaviour of older people" and emphasise the importance of involving the user "before a product-idea even exists". While Ehn [10] stresses that shared activity promotes better understanding of good design and reports on the positive impact of involving people in "design by doing" rather than in the straightforward provision of information.

The Centre of Applied Gerontology in Birmingham, UK was a pioneer in the involvement of older people in the evaluation and design of products and their "Panel of 1000 elders" continues to contribute actively [11]. A further example of how older users have been involved in research in the UK is the New Design for Old project promoted by the Royal Society for the encouragement of Arts, Manufactures and Commerce [12]. With the support of the Helen Hamlyn Foundation, DesignAge was set up in the early 1990s at the Royal College of Art. Its aim was to focus on the needs of the older user and demonstrate that: "design with older people in mind can be multi-generational, inclusive, universal and in every sense better design" [13]. DesignAge is now a partner in further research funded by the EPSRC, which with other partners, is extending the involvement of users in the design process through a project called "i design" The user-philosophy of the project has been described as:

"Working with older people is probably the best way to confront prejudice and the best way to develop the high quality products and services that we will all benefit from in the future. In addition, putting the user first is the best way of putting technology in its place ... Technology must service people, and for that reason I stress the concept of older people as 'critical users and as critical consumers ... if we think that we will succeed by prescribing for older people, then we make a big mistake." [6].

\subsection{The focus group methodology in AT research}

A focus group is a group interview that is focused on a particular topic and facilitated or co-ordinated by a moderator. This methodology is widely used in qualitative social science and market research and aims to capitalise on the interaction that occurs within the group. Focus groups have been advocated in health care research in order to study consumer satisfaction and quality assurance [14]. Focus groups are useful at any point in a research program. Early on in the research process focus groups can offer exploratory research where little is known about the phenomenon of interest. Later on in the research process focus groups may be used in order to add depth to responses [15]. In considering the advantages of focus groups, Stewart and Shamdasani [16] note that using a focus group allows the researcher to interact with respondents to clarify responses, and follow up questions. Focus groups are a useful tool in terms of design and development of new products. They are a valuable technique for sounding out people on new ideas and enabling relevant ideas and preferences to be explored without making assumptions about respondents' views [17].

In assistive technology research, focus groups have been used to explore a range of views. For example Angelo et al. [18] describe how focus groups with Occupational Therapists were used to explore their views regarding what constituted best practice in Assistive Technology evaluation. A further example of how focus groups have been used in assistive technology research projects is the European project called ACTION (Assisting Carers using Telematic Interventions to meet Older persons Needs) [19]. User requirements and attitudes towards technology were explored using focus group discussion with family and professional carers. The discussions revealed that while some participants expressed concerns about technology, the majority took a pragmatic attitude and believed that modern technology could have a positive impact on their life.

\subsection{Assistive technology research and mobility related problems}

The mobility of older people is a concern for health care providers, particularly in relation to falls [20,21]. Recent research, undertaken for the Department of Trade and Industry in the United Kingdom, on falls on stairs and steps in the home shows that two thirds of the deaths and very serious injuries resulting from falls happen to people over the age of 65 [22,23]. Although the number of falls declines with age, both the death and injury rate increases sharply with age. Falls are therefore a major issue for health care providers because of increased morbidity and consequent health care costs, and can be a precursor to a move to residential care. Consequently, a large amount of work is being done trying to reduce the incidence of falls $[22,24]$ and 
it would seem appropriate that Assistive Technology research should also address this area.

Whilst older people have been involved in the general design process of new products, there is little reported evidence of older people being involved in focus groups with the specific aim of initiating the design of new assistive technologies. In this article, we will report on a study that used focus groups to explore older users' perspectives on indoor mobility related assistive technology.

\section{Methods}

The research project was funded by the Engineering and Physical Science Research Council (EPSRC) as part of the EQUAL (Extending Quality of Active Life) programme and represented a three-way partnership between gerontologists, engineers and older users. The three main objectives of the project were:

1. to explore, through focus group discussions the extent to which older people themselves can identify and describe the nature of the indoor mobility-related problems which they encounter, and can put forward ideas for their resolution which might usefully be addressed by innovative assistive technology research and development

2. to use and build on these views, where appropriate, to make proposals for further research and the development of products in assistive technology

3. to obtain the older people's responses to these proposals.

In order to meet the objectives of the project, the research was conducted in three distinct phases: phase one involved focus groups, phase two involved the development of demonstrator products that the engineers developed in response to these, while phase three involved informal trials of these products. The project was conducted between October 1999 and December 2000.

The purpose of the first phase of the project was to explore the extent to which older people could identify and describe the nature of the mobility-related problems that they encounter, and put forward ideas for their resolution, which might usefully be addressed by innovative assistive technology research. In this paper we will describe the focus group methodology used to achieve the aims of this first phase of the study. The results obtained from the focus groups will be presented in order to facilitate a discussion regarding the extent to which the focus group methodology enabled older people to identify and describe their mobility related problems and put forward ideas for their resolution.

\subsection{Participants}

Four focus groups were convened and each group took part in the discussions and informal trials. Two were local Age Concern groups (Bexley and Islington), one was a group attending the Lister Day Hospital at Stevenage (recruited through the Hertfordshire Health Promotion Group) and the fourth was the University of the Third Age in London Design Group.

Prior to taking part in the focus groups, participants were asked to complete a questionnaire that collected demographic information such as age and gender as well as information about their general health and functional ability. The questions about functional ability were adapted from the EASYcare Assessment protocol, developed as part of a European wide project based at the University of Sheffield [25]. Altogether, 37 people participated in these four groups. All but one were aged 70 or over and $57 \%(n=21)$ were aged 80 and over; $82 \%$ ( $n=30$ ) were women. Scores from the EASYcare assessment schedule revealed that the majority of participants could only undertake basic activities of daily living with difficulty and a good number could not do it without help. This applied particularly to shopping, getting around indoors, using the bath and getting up and down stairs. The combined disability scores of all participants revealed that there were a minority of severely disabled people (scoring 25 or more out of 40$)$; just under a half $(n=16)$ had some moderate disabilities; around a quarter had minimum disability.

\subsection{Procedure}

The procedure for each of the four groups was identical and lasted approximately 60 minutes. There were five distinct stages of the procedure:

1. Introduction

2. Illustrated story and sorting pictures

3. Discussion of mobility problems

4. Discussion of solutions: existing and new

5. Summing up

After a short welcome and introduction the group convenor explained that the aim of the session was to try and learn from them, so that the engineers could be guided in their research at its earliest stages by their direct understanding of user needs. She explained that the research team were interested in solutions which have already been experienced by the group (both good and bad) as well as new or "how about this" solutions. 
To focus the discussion, group members were given an envelope containing eight cards, all of which depicted an activity in or around the home that required mobility. The focus was reinforced by one of the engineers asking the participants to imagine the following scenario:

"You have a dream about a rather ordinary day, which, like dreams often do mixes up things you used to do and things you do now. It includes features of your own home, and the houses you used to live in. Imagine yourself in this 'dream' day and think about actually doing the things we are going to describe. Think a little about how easy or how difficult you are finding these activities. To help prompt our recollections later we will illustrate some of the activities as we go on."

These activities were illustrated within the context of a "story". At the end of the story there was an opportunity to recap on each activity within the story. When the story was finished, participants were asked to place the three cards, which presented the most "difficulty" to them individually, on a table. With everyone then able to see the choices, the group were then invited to discuss the choices that they had made with a focus on three particular questions:

- Which tasks are most difficult?

- What equipment/current solutions are used at the moment to help with these problems?

- What new technologies or solutions would help?

The discussions were recorded both manually by one of the researchers and on a tape-recorder. At the end of the discussions the group convenor summed up the purpose of the focus groups and reminded the group that there would be another meeting (phase three: informal trials of products developed in response to phase one discussions). At the end of the session each participant was given a small gift token.

\subsection{Materials}

The activities depicted on the eight cards were: getting out of bed, going down stairs, reaching and bending, carrying things to the table, answering the door, moving chairs, getting in and out of a car and walking outside. The choice of mobility-related activities that were depicted on the cards reflected the definitions of mobility given by Martin et al. [26], the coding in the International Classification of Impairment, Disability and Handicap [27] as well as the questions in the EASYcare schedule [25] (see Table 1).

\section{Results}

The results presented will be used to answer the three questions posed in the focus groups: Which tasks are most difficult? What equipment/current solutions are used at the moment to help with these problems and what new technologies or solutions would help?

\subsection{Which tasks are most difficult?}

The results from the phase one focus group discussions showed that the older participants identified clearly the nature of the mobility related problems that they experienced. In addition to those depicted in the eight cards, problems mentioned included eating and food preparation, getting in and out of baths and showers, problems with eyesight and problems finding information about mobility-related equipment. The activities that were more frequently identified by focus group members as difficult were bending and reaching and climbing stairs. The activities that were less frequently identified by focus group members as difficult were eating/food preparation and carrying things. Finding information was an evident problem that emerged in the course of the discussion.

In describing their bending and reaching problems the older users gave descriptions of their physical functions and abilities. For example:

"I can't reach things easily. I have two stiff hips and am always worried about bending"

"I can't reach things and can't bend because of my hip"

"I have trouble lifting my arms up and bending down"

"I must not kneel down after my knee and hip operations."

They also outlined the problems they had with the current design of their living environment:

"Kitchen cupboards only seem to allow you to put shelves in one place."

"The top of cupboards and even the higher shelves are harder to reach."

"In the kitchen Ifeel that deep drawers are needed and not floor cupboards. You always seem to want what is at the back and I can't get down on my knees."

"They always seem to make cupboards so high."

Some group members also commented on what they perceived to be problems with existing assistive technologies or devices that they could use to solve their bending and reaching problems: 
Table 1

Linking the ICIDH-2, OPCS and EASYcare descriptions of mobility to the eight activity cards

\begin{tabular}{|c|c|c|c|c|}
\hline & Activity illustration & EASYcare questions & OPCS & ICIDH 2 \\
\hline & Getting up & & & \\
\hline 1 & Getting out of bed & $\begin{array}{l}\text { 17: move from bed } \\
\text { to chair }\end{array}$ & $\begin{array}{l}\text { PC2/6: getting in \& out } \\
\text { of bed or chair }\end{array}$ & a30500 Transferring oneself while sitting or lying \\
\hline \multirow[t]{3}{*}{2} & Going downstairs & 16: manage stairs & L5/10 twelve stairs & $\begin{array}{l}\text { a40100 Moving around in the general environment } \\
\text { a40200 Climbing }\end{array}$ \\
\hline & Household tasks & 10: go shopping & & $\begin{array}{l}\text { a60100 Procuring and taking care of daily necessi- } \\
\text { ties (including shopping and clothing) }\end{array}$ \\
\hline & & 12: use telephone & & $\begin{array}{l}\text { a90700 Using aids for communication, information } \\
\text { and signalling }\end{array}$ \\
\hline \multirow[t]{3}{*}{3} & Reaching and bending & 8: do housework & $\begin{array}{l}\text { RS 4/8: reach above } \\
\text { head }\end{array}$ & a30700 Activities involving arm and coarse hand use \\
\hline & & & & $\begin{array}{l}\text { a40100 Moving around in the general environment } \\
\text { a60500 Taking care of dwelling }\end{array}$ \\
\hline & Getting lunch for a friend & 9. nrenare own meals & L. hold on to keen & 30400 Walking and related activities \\
\hline 4 & & $\begin{array}{l}\text { 9: prepare own meals } \\
\text { 15: get around indoors }\end{array}$ & $\begin{array}{l}\text { b4: hold on to keep } \\
\text { L8/11 bend down } \\
\text { straighten up } \\
\text { D1-D11 Dexterity }\end{array}$ & $\begin{array}{l}\text { a40100 Moving around in the general environment } \\
\text { a50700 Dealing with everyday objects and appli- } \\
\text { ances } \\
\text { a90500 Using aids for housekeeping }\end{array}$ \\
\hline \multirow[t]{2}{*}{5} & Answer the door & 15: get around indoors & $\begin{array}{l}\text { PC2/6: getting in \& out } \\
\text { of bed or chair }\end{array}$ & a30300 Changing a body position \\
\hline & & & & $\begin{array}{l}\text { a90700 Using aids for communication, information } \\
\text { and signalling }\end{array}$ \\
\hline \multirow[t]{2}{*}{6} & Moving chairs & 22: feed self & D5: serving/ pouring & $\begin{array}{l}\text { a30700 Activities involving arm and coarse hand use } \\
\text { a30800 Activities aimed at making objects move } \\
\text { a50500 Eating and drinking } \\
\text { a80600 Personal social activities }\end{array}$ \\
\hline & Going out & & & \\
\hline 7 & Getting in and out of a car & & & $\begin{array}{l}\text { a40100 Moving around in the general environment } \\
\text { a40500 Using transportation }\end{array}$ \\
\hline 8 & Walking outside & 14: walk outside & L2/6/14 walking ability & $\begin{array}{l}\text { a30400 Walking and related activities } \\
\text { a40300 Moving around in specified environments } \\
\text { a80600 Personal social activities }\end{array}$ \\
\hline
\end{tabular}

"The Gripper is awkward when cooking."

"I have a stool/step ladder. The problem is that is has no handle at the top."

"I can't stand on a chair because I get giddy."

Most of the groups agreed that they would not use steps to reach something because they felt it was too risky. Closely linked to this discussion was an identified fear of falling or hurting themselves:

"I am often scared to use a ladder to get to high cupboards as if I fall no one will be there."

"You're frightened to chance it, so you don't do it."

"I wouldn't use steps even if I knew someone would be coming along in a couple of hours."

In describing their problems with steps or stairs the focus group members discussed their general difficulties as well as the differences between going up and down stairs: For example:

"It's harder to get up them than go down"

"I can't get up and down the stairs".
"Going down stairs presents different problems to going up stairs”.

"Going downstairs is a complicated physical act and can be painful”.

"My knee hurts when I go downstairs but that is my own personal worry."

The group members described how they tried to cope or adapt to their problems:

"I need to press on something to help me with the stairs."

"I can climb stairs as long as I hang on to the sides.”

"Trouble with stairs. I have to hold the banister rail and step up sideways."

They also indicated what they felt was wrong with current assistive technologies and environmental designs:

"I can' thave a stair lift as the stairs are not wide enough" [person has to keep leg straight due to an accident] 
"One thing that is lethal is having one step in a series that is a different height to the others."

"The criss-cross design in the British Library tends to hide the steps and gives a loss of orientation."

"The Sainsbury Wing [National Gallery] has a

lethal staircase. It is wide steps and no banisters."

In describing their information problems the focus group members commented on their desire to have more information on assistive technology products in order to make informed decisions about whether to purchase them:

"Many things exist but we need more information."

"You need to see things to find out what you are buying."

The also indicated what they felt was wrong with current methods of information provision:

"People don't know where to get information from."

"We don't get to see these catalogues."

"The stores are always aimed at disabled and I don't want to go in there."

"Devices are only shown in shops where you feel that you're one step away from the hospital"

"I can' t see the catalogues because of my eyesight."

\subsection{Current or existing solutions to identified problems}

The focus groups were able to identify a number of existing solutions to their bending and reaching and stair climbing problems. Identified solutions to bending and reaching problems focused on adding to or adapting existing equipment and using existing devices such as grippers. Identified solutions to climbing stairs focused on coping and adapting own movement; getting help from others as well as existing devices such as stair lifts (see Table 2).

The group members were less able to identify existing solutions to their information needs, what comments they did make, referred to the help that people could give:

"Therapists have been very helpful."

"The Council will advice people on what is available and where to get information."

\subsection{New solutions to identified problems}

The focus groups were able to identify a number of potential solutions to their bending and reaching, stair climbing and information problems. Potential solutions to bending and reaching problems focused on lifting people to the height they wished to be and providing something to hold on to. Potential solutions to climbing stairs focused on the position and design of banisters and hand-rails. Potential solutions to information problems focused on increasing the profile and accessibility of equipment (see Table 3 ).

\section{Discussion}

In this paper we have described how we used a focus group methodology in order to try and enable older people to identify and describe their mobility related problems as well as put forward possible ideas for the resolution of these problems. We will now discuss the results obtained from the focus groups in order to reflect on how useful and valuable the focus group methodology is in enabling older people to become involved in assistive technology research.

\subsection{Did the focus group methodology enable older people to identify and describe their mobility related problems?}

The researchers feel that the eight picture cards used in the focus groups were a useful tool for focusing the discussion on mobility problems. However, within the focus groups, participants also explored issues that were not necessarily suggested by the picture cards. Issues such as food preparation, getting in and out of baths, problems with eyesight, problems finding information and fear of falling were all raised. This could suggest a potential benefit of the focus group methodology used in that it appears to have been flexible enough to allow individuals to raise any of their concerns and for group members to react to and build on responses to these concerns [16]. It could be argued that such flexibility may have enabled the discussions that occurred within the groups to address important issues that the researchers might otherwise have ignored. Whilst this flexibility could be seen as an advantage, it could also be interpreted as evidence that at times participants found it difficult to focus on the general agenda as set by the picture cards. This might be because they found it difficult to relate to a problem if they had not experienced it directly or recently. Further exploration is needed therefore in order to validate the choice of picture cards and to assess the extent to which the composition of the focus groups influences the results obtained. 
Table 2

Focus group results: current or existing solutions to identified problems

\begin{tabular}{|c|c|}
\hline Bending and reaching & Climbing stairs \\
\hline $\begin{array}{l}\text { ADDING TO OR ADPATING EXISTING EQUIPMENT: } \\
\text { I've put turntables into my cupboards to help me find the things I } \\
\text { want more easily } \\
\text { Turntables are good } \\
\text { Some cookers are also badly designed. The ovens are almost at } \\
\text { ground level and very difficult to reach. I have put mine on a platform } \\
\text { to raise it up. } \\
\text { I've got a wall-mounted oven and wouldn't change it for the world. } \\
\text { It is a good height. } \\
\text { I converted an osteopath table into a table for home use. The height } \\
\text { is adjustable with a foot lever. It costs } 500 \text { pounds. } \\
\text { Need fridge etc. on a plinth so I can reach things. } \\
\text { USING ASSISTIVE TECHNOLOGIES: } \\
\text { I've got a lovely stick with a grabber } \\
\text { I've got my feather duster on a very long stick } \\
\text { I've got a good reacher from the hospital }\end{array}$ & $\begin{array}{l}\text { COPING AND ADAPTING: } \\
\text { Can be better to go down backwards } \\
\text { Good foot up and bad foot down } \\
\text { HELP FROM OTHERS: } \\
\text { You get training at the hospital for doing the stairs } \\
\text { EQUIPMENT \& DESIGN: } \\
\text { I've got a stair lift, that's lovely } \\
\text { Grip rails are good as long as they are small enough to get your hand } \\
\text { around. Need to have one either side. I use the rail to pull myself up } \\
\text { the stairs } \\
\text { Wide shallow steps are good. It can be frightening if the stairs are } \\
\text { too steep and you are looking down as you walk. The Barbican steps } \\
\text { near the fountain are excellent. } \\
\text { Handrail on opposite side of banister is a great help }\end{array}$ \\
\hline
\end{tabular}

Table 3

Focus group results: overview of suggested assistive technology solutions

\begin{tabular}{ll}
\hline Activity & Suggestion for possible new solutions to identified problems (example comments) \\
\hline Climbing stairs & Non slip banisters would be useful. You could be wearing gloves for example, but if the banister has small knobs \\
on it you would only slip a few inches if you lost grip. & Grip rails are good as long as they are small enough to get your hand around. Need to have one on either side. I use \\
the rail to pull myself up the stairs. & Handrail on opposite side of banister is a great help \\
& Can be better to go down backwards. \\
Bending and reaching & I'd like a little pair of steps with sides to help me get to the curtains for example. \\
& How about a sort of forklift truck idea? It could lift you up on a platform to reach the higher cupboards. \\
& I cannot climb on to chairs and ladders. I like the idea of a lifting platform but you could also have adjustable tables \\
& and surfaces. Also a car jack type product would be useful when cleaning under furniture. \\
& It is necessary to have something to hold on to. For example the use of poles like you find in the Underground. \\
& Put shelves on a pulley \\
& Somebody once started a dictionary of well-designed products. Many things exist but we need more information. \\
Should have an "easy gadget" section in department stores. & TV producers could be approached. A show once or twice a year showing available technology would be useful. \\
You would also need details of where to get them. \\
Need to see things to find out what you are buying. \\
Need somebody with you for a day to see how you manage little things. They would understand your situation.
\end{tabular}

\subsection{Did the focus group methodology enable older people to put forward possible ideas for the resolution of their mobility related problems?}

The results from the focus groups suggest that the methodology used enabled older people to demonstrate their ability to be creative problem-solvers. This creativity can be seen in the pragmatic low-tech solutions that were proposed as well as the more "high-tech" solutions such as a lifting platform to reach higher cupboards. Some of the suggestions that were made appear to have been influenced by existing devices that the older people had seen being used in other contexts, for example, "a pole to hold on to like in the Underground". Such results however, do appear to reflect the current recognition that older people can be critical and active consumers of assistive technologies $[3,4]$.

The detail of the comments made by the focus group members regarding their mobility-related problems did allow possible solutions to be identified. For example, the issue of reaching cupboards and shelves suggested that developing moving cupboards might be useful. Whilst the issues surrounding fear of falling suggested two possible solutions: vertical grab poles for the kitchen or a "sinker and lifter". But although the focus group methodology enabled the identification of a number of solutions, it did not provide a framework to enable the researchers to decide which solutions to explore further. For example, the researchers decided not to explore moving cupboards any further because 
they considered that solutions had already been developed such as the Rowntree House at York [28]. They did decide however, that it would be useful to explore a stair climbing aid in more detail. While lifts are expensive and any device using power has inherent danger, the researchers considered that it might be possible to devise a support that would improve safety and encourage a user to use what power they had. On reflection, it may have been useful to ask the focus group participants to validate these decisions. This would suggest that the focus group methodology could be extended to include a presentation and discussion of the shortlist of potential solutions in order to identify priorities, highlight existing solutions that the participants may be unaware of and clarify the extent to which the short-list of potential solutions reflects individual or wider group experiences.

\section{Conclusions}

The results from the focus group discussions suggest that the methodology used did enable older people to identify and describe the nature of their indoor mobility-related problems and use these as a basis for suggesting ideas for their resolution which might usefully be addressed by innovative assistive technology research and development. Further exploration of the methodology is required however in order to validate the choice of picture cards; assess the extent to which the composition of the focus groups influences the results obtained and decide which of the suggested solutions should be taken further in the design and development process. The researchers consider that the focus group methodology has enabled them to do as Stern (1994) urges: "listen to the technology user and learn".

\section{Acknowledgements}

The authors are grateful to Professor Janet Askham (Age Concern Institute of Gerontology, King's College London), Phillip Blake, Douglas Cartwright, and Lucy Porter (Centre of Rehabilitation Engineering, King's College London), Professor Helen Petrie (University of Hertfordshire), for their contributions to this research. The authors would also like to thank the organisers and older participants in the research at Age Concern Bexley, Age Concern Islington, the Lister Day Hospital Stevenage and the University of the Third Age in London Design Group for their invaluable help.

\section{References}

[1] R. Baldursdottir, R. Flo, T. Hurnasti, L. Jensen and K. Sandberg, User Involvement in the development of assistive technology in the Nordic countries (USDAT), in: Assistive Technology-Added Value to the Quality of Life, C. Marincek, C. Buhler, H. Knops and R. Andrich, eds, IOS Press, Amsterdam, 2001.

[2] C. Buhler, Guidelines for participation of users with disabilities in R\&D projects, in: Assistive Technology-Added Value to the Quality of Life, C. Marincek, C. Buhler, H. Knops and R. Andrich, eds, IOS Press, Amsterdam, 2001.

[3] T. Barnea, Technology and aging: research aims of the JBCBrookdale Institute, in: Technology and Aging, T. Barnea and E. Stern, eds, JBC-Brookdale Institute, Jerusalem, 1994.

[4] I. Mizrahi, Consumer groups of elderly people: operation and findings, in: Technology and Aging, T. Barnea and E. Stern, eds, JBC-Brookdale Institute, Jerusalem, 1994.

[5] H. Petrie, User-centred design and evaluation of adaptive and assistive technology for disabled and elderly users, Informationstechnik und Technische Informatic 39 (1997), 7-12.

[6] R. Coleman, Improving the quality of life for older people by design, in: Gerontechnology: a sustainable investment in the future, J Graafmans, V. Taipale and N. Charness, eds, IOS Press, Amsterdam, 1998.

[7] E. Stern, Technology, ageing and disability: from theory to practice, in: Technology and Aging, T. Barnea and E. Stern, eds, JBC-Brookdale Institute, Jerusalem, 1994.

[8] J.S. Sandhu, What is design for all? in: Improving the quality of life for the European Citizen, I. Placencia Porrero and E. Ballabio, eds, IOS Press, Amsterdam, 1998.

[9] J. Rietsema and A.S. Melenhorst, User involvement in gerontechnology: early stage user-understanding to empower technology development, in: Improving the quality of life for the European Citizen, I. Placencia Porrero and E. Ballabio, eds, IOS Press, Amsterdam, 1998.

[10] P. Ehn, Scandinavian Design: on participation and skill, in: Participatory design: principles and practice, D. Schuler and A. Namioka, eds, Lawrence Erlbaum Associates, New Jersey, 1993.

[11] U.S.L. Nayak, Design participation by the thousand elders, in: Gerontechnology: a sustainable investment in the future, J. Graafmans, V. Tiapale and N. Chaness, eds, IOS Press, Amsterdam, 1998.

[12] S. Hewer and C. Kingsland, Inspiring the young, in: Gerontechnology: a sustainable investment in the future, J. Graafmans, V. Tiapale and N. Chaness, eds, IOS Press, Amsterdam, 1998.

[13] R. Coleman, Designing for our future selves, Access by Design 58 (1998), 10-11.

[14] J. Kitzinger, Introducing Focus Groups, British Medical Journal 311 (1995), 299-302.

[15] J. Seale and S. Barnard, Therapy Research: Processes and Practicalities, Butterworth-Heinemann, Oxford, 1998.

[16] D.W. Stewart and P.N. Shamdasani, Focus Groups: Theory and Practice, Sage Publications, London, 1990.

[17] D. McDonagh-Philp and A. Bruseberg, Using focus groups to support new product development, Engineering Designer: Institution of Engineering Designers Journal 26 (2000), 4-9.

[18] J. Angelo, M.E. Buing, M. Schmeler and S. Doster, Identifying best practice in the Occupational Therapy Assistive Technology Evaluation, American Journal of Occupational Therapy 51 (1997), 916-920. 
[19] L. Magnusson, H. Berthold, L. Brito, M. Chambers, D. Emery and T. Daly, ACTION: Assisting Carers using Telematics Interventions to meet Older persons' Needs, [WWW document] URL http://www.hb.se/action/ [03/04/01].

[20] S. Kinn and L. Galloway, Do Occupational Therapists and Physiotherapists teach elderly people how to rise after a fall? British Journal of Occupational Therapy 63 (2000), 251-259.

[21] C. Ballinger and S. Payne, Falling from Grace or into Expert Hands? Alternative Accounts about Falling in Older People, British Journal of Occupational Therapy 63 (2000), 573-579.

[22] Department of Trade and Industry: Avoiding slips, trips and broken hips. Step up to safety, [WWW document] URL http://www.preventinghomefalls.gov.uk. [19/05/01].

[23] L.D. Hill, R.A. Haslam, K. Brooke-Wavell, P.A. Howarth and J.E. Sloane, How do older people use their stairs? Working with older people 4 (2000), 24-27.

[24] L. Mackenzie, J. Byles and N. Higginbotham, Designing the Home Falls and Accidents Screening Tool (HOME FAST): Selecting the Items, British Journal of Occupational Therapy 63 (2000), 260.

[25] EASYcare, Elderly Assessment System, [WWW document] URL http://www.bbr-online.com/easycare [19/05/01].

[26] J. Martin , H. Meltzer and D. Elliot, The prevalence of disability among adults. OPCS survey of disability in Great Britain Report 1, HMSO, London, 1988.

[27] World Health Organisation, ICIDH-2: International Classification of Functioning and Disability Beta-2 Draft, WHO, 1999.

[28] T. Venables and C. Taylor, Smarthomes: A specification guide, Joseph Rowntree Foundation, York, 2001. 